\title{
Zasady kwalifikacji do ECMO u osób dorosłych
}

\section{Recommendations for the clinical application of ECMO in adults}

\author{
Adam Arendarczyk, Radosław Wilimski, Michał Michniewicz, Paweł Czub, Piotr Hendzel \\ Klinika Kardiochirurgii I Katedry i Kliniki Kardiologii Warszawskiego Uniwersytetu Medycznego
}

\section{Streszczenie}

Ciągłe pozaustrojowe natlenianie (oksygenacja) krwi (ECMO) stosuje się w skrajnych przypadkach niewydolności oddechowej i/lub krążeniowej, opornych na konwencjonalne metody leczenia. Wraz z postępem nauki i zdobywaniem doświadczenia rozpoczęto stosowanie tej metody także w leczeniu najgłębszych stadiów wychłodzenia oraz podczas przygotowania do planowanego przeszczepienia serca i/lub płuc. Ze względu na restrykcyjne wskazania i inwazyjny charakter leczenia ECMO wykorzystuje się stosunkowo rzadko. Niejednokrotnie jednak stanowi decydujący o przeżyciu i dalszych możliwościach leczniczych element terapii pacjenta.

Słowa kluczowe: ECMO, ECLS, krążenie pozaustrojowe, pozaustrojowa oksygenacja membranowa krwi

Folia Cardiologica 2017; 12, 7: 113-117

\section{Wstęp}

Od ponad 60 lat widać zarówno ewolucję aparatów do prowadzenia krążenia pozaustrojowego, jak i wpływ tych urządzeń na rozwój kardiochirurgii i intensywnej terapii. Kamieniami milowymi w rozwoju metod krążenia pozaustrojowego były wyizolowanie heparyny przez Jaya McLeana w 1916 roku, skonstruowanie oksygenatora membranowego przez Theodora Kolobowa w 1963 roku oraz stworzenie w latach 70. ubiegłego wieku pierwszego mobilnego aparatu do prowadzenia długotrwałego pozaustrojowego natleniania krwi (ECLS, extracorporeal life support; ECMO, extracorporeal membrane oxygenation) [1].

\section{Jak działa ECMO?}

Działanie ECMO polega na wykorzystaniu krążenia pozaustrojowego do utlenowania krwi i eliminacji z niej dwutlenku węgla w oksygenatorze. W trakcie krążenia pozaustrojowego możliwa jest regulacja prędkości przepływu krwi oraz dokładna kontrola jej temperatury. Krew do aparatu ECMO i z niego jest transportowana systemem kaniul z two- rzywa sztucznego. W celu ograniczenia ryzyka tworzenia się skrzepów krwi podczas krążenia pozaustrojowego konieczne jest odpowiednie leczenie przeciwkrzepliwe heparyną niefrakcjonowaną z utrzymywaniem wskaźnika aktywowanego czasu krzepnięcia (ACT, activated clotting time) na poziomie $180-220 \mathrm{~s}$ [2].

\section{Rodzaje konfiguracji ECMO}

Zależnie od choroby podstawowej i oczekiwanego efektu stosuje się dwie główne konfiguracje ECMO:

- żylno-żylną, polegającą na umieszczeniu kaniuli w żyle szyjnej i/lub udowej lub zastosowaniu specjalnej kaniuli dwuświatłowej wprowadzonej do żyły szyjnej. Ta opcja jest stosowana w przypadku ciężkiej niewydolności oddechowej bez komponenty niewydolności krążenia. Nadrzędny cel terapii stanowią dostarczenie organizmowi tlenu i eliminacja dwutlenku węgla. Natlenowana krew z oksygenatora jest transportowana z powrotem do układu żylnego, a następnie - przez prawidłowo działający mięsień prawej komory - do płuc, lewego przedsionka, lewej komory i aorty; 
- tętniczo-żylną, polegającą na umieszczeniu kaniuli żylnej w żyle szyjnej i/lub udowej oraz kaniuli tętniczej $w$ tętnicy udowej. Natlenowana krew w tej konfiguracji jest podawana przeciwnie do fizjologicznego przepływu krwi w aorcie. Tego typu kaniulację naczyń stosuje się w przypadku współistniejącej niewydolności układów oddechowego i krążenia. Jeśli zapadnie decyzja o konieczności zastosowania ECMO podczas operacji kardiochirurgicznej, to kaniule można wyprowadzić bezpośrednio z klatki piersiowej (najczęściej z prawego przedsionka serca i aorty wstępującej). Podawanie utlenowanej krwi do układu tętniczego z odpowiednią energią kinetyczną, generowaną przez pompę aparatu ECMO, wspomaga przepływ krwi, którego nie jest w stanie zapewnić mięsień sercowy [3].

W każdym typie konfiguracji ECMO jest możliwe wykorzystanie mniej inwazyjnych, przezskórnych technik kaniulacji żyınej i tętniczej.

\section{Funkcje ECMO}

Długotrwałe pozaustrojowe natlenianie krwi stwarza warunki do regeneracji i dalszego leczenia. Umożliwia wstępną stabilizację stanu chorego i podjęcie kolejnych działań terapeutycznych optymalizujących postępowanie medyczne. Zapewnia dokładną kontrolę procesu regulacji temperatury krążącej krwi za pomocą zewnętrznego wymiennika ciepła, co pozwala przeprowadzić procedurę ogrzewania pozaustrojowego pacjentów w stanie głębokiego wychłodzenia [4]. Zadaniem krążenia pozaustrojowego wykorzystywanego w celu przeprowadzenia operacji kardiochirurgicznej jest zastąpienie pracy serca i płuc jedynie w czasie wykonywania procedury kardiochirurgicznej. Z kolei ECMO wykorzystuje się głównie do długotrwałego wspomagania oddychania w okresie od kilku dni do nawet kilku tygodni.

\section{Wskazania do stosowania ECMO u dorosłych}

Wskazania do zastosowania terapii ECMO u osób dorosłych przedstawiono w tabeli 1.

\section{Niewydolność oddechowa}

Ciężka, odwracalna niewydolność oddechowa jest najczęstszą przyczyną wdrożenia procedury ECMO. Głównym kryterium konieczności zastosowania tej metody jest ryzyko zgonu pacjenta określane za pomocą wskaźnika oksygenacji krwi $\left(\mathrm{PaO}_{2} / \mathrm{FiO}_{2}\right)$ oraz skali uszkodzenia płuc (skala Murraya) (tab. 2) [5]. Skala Murraya jest oparta na ocenie badania radiologicznego klatki piersiowej, stopnia nasilenia hipoksemii, wartości dodatniego ciśnienia końcowo-wydechowego (PEEP, positive end-expiratory pressure) w czasie wentylacji mechanicznej oraz wskaźnika podatności płuc [6].

Przyczyną ostrej niewydolności oddechowej wymagającej wdrożenia ECMO jest najczęściej ciężkie zapalenie płuc o etiologii wirusowej (wirus grypy A/H1N1) i bakteryjnej oraz zespół ostrej niewydolności oddechowej (ARDS, acute respiratory distress syndrome) rozwijający się w wyniku posocznicy, urazu, zatrucia środkami wziewnymi lub po masywnych przetoczeniach krwi [7].

Terapia ECMO znajduje zastosowanie w przypadkach masywnego przecieku powietrza poza tkankę płucną (gdy wydechowa objętość powietrza stanowi < 50\% objętości wdechowej). W takiej sytuacji ECMO rozpoczyna się bezpośrednio po odbarczeniu odmy za pomocą drenażu czynnego [2].

W sytuacji izolowanej niewydolności oddechowej bez niewydolności krążenia stosuje się żylno-żylną konfigurację ECMO. Po podłączeniu urządzenia funkcję płuca przejmuje zewnętrzny oksygenator, który zapewnia odpowiednią wymianę gazową. Natlenowana krew jest podawana do układu żylnego, gdzie zostaje ponownie dostarczona do organizmu przez prawidłowo kurczący się mięsień sercowy.

Jednocześnie z pozaustrojową oksygenacją krwi stosuje się oszczędzającą wentylację płuc (objętość oddechowa $<4 \mathrm{ml} / \mathrm{kg}$ mc., ciśnienie plateau [ciśnienie podczas pauzy końcowowdechowej] < $25 \mathrm{~cm} \mathrm{H}_{2}$ O) [8]. W trakcie terapii powinno się utrzymywać ciśnienie parcjalne tlenu we krwi tętniczej na poziomie 100-150 mm Hg [9]. Należy także stale kontrolować pH krwi oraz ciśnienie parcjalne $\mathrm{CO}_{2}$. Na początku terapii ECMO stosuje się głęboką sedację, zmniejszając ją wraz z uzyskiwaniem pozytywnych efektów

Tabela 1. Wskazania do wdrożenia procedury pozaustrojowego natleniania membranowego krwi (ECMO)

\begin{tabular}{llll}
\hline Niewydolność oddechowa & Niewydolność krążenia & Planowane przeszczepienie & Hipotermia \\
\hline Zapalenie płuc & Wstrząs kardiogenny & $\begin{array}{l}\text { Przeszczepienie serca } \\
\text { i/lub płuc }\end{array}$ & $\begin{array}{l}\text { Temperatura wewnętrzna } \\
\leq 28^{\circ} \mathrm{C}\end{array}$ \\
$\begin{array}{l}\text { Zespół zaburzeń ostrej niewydol- } \\
\text { ności oddechowej (ARDS) }\end{array}$ & Kardiomiopatia & \\
& $\begin{array}{l}\text { Zapalenie mięśnia sercowego } \\
\text { Zatorowość płucna }\end{array}$ & \\
ARDS - acute respiratory distress syndrome & &
\end{tabular}


Tabela 2. Wskazania do wdrożenia ECMO w niewydolności oddechowej

RYZYKO ZGONU 50-80\% gdy:
$\mathrm{PaO}_{2} / \mathrm{FiO}_{2}<150$ przy FiO
i/lub
Murray score $2-3$
RYZYKO ZGONU $\geq 80 \%$ gdy:
$\mathrm{PaO}_{2} / \mathrm{FiO}_{2}<100$ przy FiO $\mathrm{F}_{2}>0,9 \rightarrow$ NALEŻY PODŁACZYĆ ECMO
i/lub
Murray score $3-4$
Mimo optymalnej terapii oddechowej $\geq 6 \mathrm{~h}$

leczenia, dążąc tym samym do uzyskania wydolnego oddechu własnego pacjenta.

\section{Niewydolność serca}

Wskazaniem do zastosowania pozaustrojowego natleniania krwi jest niewydolność serca występująca najczęściej pod postacią wstrząsu kardiogennego, opornego na optymalne leczenie przyczynowe i farmakologiczne [10]. Terapia ECMO powinna być rozważana na wczesnym etapie leczenia pacjenta niestabilnego hemodynamicznie, z niskim ciśnieniem skurczowym, niskim rzutem serca i w konsekwencji niedostateczną perfuzją tkankową, u którego nie uzyskuje się stabilizacji klinicznej mimo optymalnego leczenia farmakologicznego oraz często wspomagania serca kontrapulsacją wewnątrzaortalną. Najczęstsze przyczyny ostrego wstrząsu kardiogennego przedstawiono w tabeli 3. W przypadku niewydolności krążenia stosuje się konfigurację tętniczo-żylną ECMO z umieszczeniem kaniuli tętniczej w tętnicy udowej, a kaniuli żylnej - w żyle szyjnej lub udowej. Jeżeli wstrząs kardiogenny wystąpił śródoperacyjnie (podczas operacji kardiochirurgicznej), to można umieścić kaniulę żylną w prawym przedsionku, a kaniulę tętniczą w aorcie wstępującej. Dzięki temu zostaje zachowany fizjologiczny kierunek przepływu krwi w aorcie [11].

Tętniczo-żylne ECMO jest metodą z wyboru w leczeniu piorunującego zapalenia mięśnia sercowego. Stan zapalny obejmujący mięsień sercowy może mieć podłoże zakaźne, immunologiczne lub toksyczne. Najczęściej występuje u młodych osób dorosłych. Od czasu pierwszego zastosowania ECMO przeżywalność pacjentów z piorunującym zapaleniem mięśnia sercowego $\mathrm{w}$ trakcie hospitalizacji osiągnęła 55-78\% [12]. Kolejnym istotnym wskazaniem do zastosowania zewnątrzustrojowej oksygenacji krwi jest wstrząs pokardiotomijny. To rzadka jednostka kliniczna charakteryzująca się nagłą niewydolnością serca w trakcie operacji kardiochirurgicznej lub bezpośrednio po niej. Wśród potencjalnych przyczyn wstrząsu pokardiotomijnego wymienia się stan ogłuszenia mięśnia sercowego, zawał lub nieodpowiednia kardioprotekcja mięśnia sercowego podczas operacji.

Szczególnym wskazaniem do zastosowania ECMO jest prawokomorowa niewydolność serca z zachowaną prawidłową czynnością lewej komory. Najczęstszą przyczyną hemodynamicznej niewydolności prawej komory jest masywna zatorowość płucna lub niedokrwienie mięśnia sercowego.

\section{Przeszczepienie płuc i/lub serca}

Mimo znacznego postępu w rozwoju transplantologii głównym problem pozostaje ograniczona liczba dawców narządów. Zastosowanie ECMO jako terapii pomostowej do czasu przeszczepienia to niejednokrotnie jedyna szansa na przeżycie dla pacjentów w schyłkowej fazie niewydolności płuc i/lub serca. Dotyczy to zarówno przeszczepienia narządów, jak i wszczepienia zaawansowanych układów mechanicznego wspomagania serca.

Szczególnym wskazaniem do zastosowania ECMO w zakresie transplantologii jest pierwotna dysfunkcja przeszczepionych płuc (PGD, primary graft disfunction). Stan ten charakteryzuje się obrzękiem płuc z rozlanym uszkodzeniem pęcherzyków płucnych, prowadzącym do postępującego niedotlenienia. Pierwotna dysfunkcja przeszczepionych płuc występuje w okresie $72 \mathrm{~h}$ od przeszczepienia narządu. Jest formą ARDS, w terapii którego stosuje się ECMO [13].

\section{Hipotermia}

Skuteczne leczenie hipotermii polega na wdrożeniu odpowiedniego sposobu ogrzewania pacjenta. Obniżenie temperatury narządów wewnętrznych spowalnia ich metabolizm i pozwala na dłuższe przeżycie w warunkach niedokrwienia. Standardy leczenia przewidują zastosowanie krążenia zewnątrzustrojowego w przypadku ciężkiej hipotermii ze spadkiem temperatury wewnętrznej nieprzekraczającym $28^{\circ} \mathrm{C}$ oraz współistniejącym upośledzeniem przytomności i cechami niestabilności hemodynamicznej (ciśnienie skurczowe < 90 mm Hg, zaburzenia rytmu serca, niewydolność oddechowa). Procedurę ogrzewania za pomocą ECMO można

Tabela 3. Najczęstsze przyczyny ostrego wstrząsu kardiogennego

\begin{tabular}{|c|c|c|c|c|}
\hline Ostry zawał serca & $\begin{array}{l}\text { Zapalenie mięśnia } \\
\text { sercowego }\end{array}$ & $\begin{array}{ll}\text { Kardiomiopatia: } \\
\text { - } & \text { rozstrzeniowa } \\
\text { - } & \text { niedokrwienna } \\
\text { - } & \text { restrykcyjna } \\
\text { - } & \text { okołoporodowa }\end{array}$ & $\begin{array}{l}\text { Niewyrównana przewlekła } \\
\text { niewydolność serca }\end{array}$ & Wstrząs pokardiotomijny \\
\hline
\end{tabular}


Tabela 4. Przeciwwskazania do pozaustrojowego natleniania membranowego krwi (ECMO)

\begin{tabular}{ll} 
Bezwzględne & Względne \\
\hline Brak zgody chorego & Przeciwwskazania do heparynizacji, tj.: \\
& $\bullet \quad$ aktywne krwawienie \\
& $\bullet \quad$ skaza krwotoczna \\
Nieodwracalność choroby podstawowej & Znacznego stopnia immunosupresja (liczba neutrofilów $\left.<400 / \mathrm{mm}^{3}\right)$ \\
Brak możliwości przeszczepienia płuc i/lub serca & Wiek > 65 lat \\
& Ciężka choroba układowa \\
& Intensywna wentylacja mechaniczna $\geq 7$ dni $\left(\mathrm{FiO}_{2}>0,9 ; \mathrm{P}_{\text {plat }}>30 \mathrm{~cm} \mathrm{H}_{2} \mathrm{O}\right)$ \\
& Otyłość
\end{tabular}

także zastosować w skrajnej hipotermii z zatrzymaniem krążenia, jeżeli ustanie akcji serca nastąpiło z powodu wychłodzenia, gdy wykluczono pewne oznaki zgonu (poważny uraz, zamarznięcie) [4].

Nagłe ogrzanie organizmu w sytuacji ciężkiego wychłodzenia prowadzi do obrzęku narządów wewnętrznych, zaburzenia równowagi wodno-elektrolitowej oraz hipowolemii powstałej wskutek nagłego rozszerzenia się łożyska naczyniowego [14]. Zastosowanie ECMO umożliwia dokładną regulację temperatury krwi za pomocą zewnętrznego wymiennika ciepła. W przypadku hipotermii kwalifikującej do włączenia krążenia zewnątrzustrojowego zaleca się ogrzewanie pacjenta $\mathrm{w}$ tempie $0,25-1,5^{\circ} \mathrm{C} / \mathrm{h}[15,16]$. Pozwala to uniknąć powikłań związanych ze zbyt szybkim wzrostem temperatury organizmu.

\section{Przeciwwskazania do ECMO}

Podjęcie decyzji o wdrożeniu ECMO jest często kompromisem między ryzykiem, jakie niesie podłączenie krążenia pozaustrojowego, a możliwymi do uzyskania korzyściami w terapii pacjenta. Zastosowanie ECMO jest często ostatnią formą terapii stwarzającą szansę na kontynuację leczenia. Z tego powodu większość przeciwwskazań do zastosowania tej metody ma charakter względny, a decyzję o rozpoczęciu ECMO powinien podjąć wielodyscyplinarny zespół lekarski [17].

Przeciwwskazania do terapii ECMO przedstawiono w tabeli 4.

\section{Wnioski}

Terapia ECMO jest zaawansowaną, złożoną i inwazyjną procedurą medyczną stosowaną w leczeniu odwracalnych stanów ciężkiej niewydolności oddechowej i/lub serca. Może również stanowić terapię pomostową do dalszych form leczenia. 0 wynikach postępowania terapeutycznego decydują prawidłowa ocena wskazań oraz odpowiedni czas rozpoczęcia terapii ECMO.

\section{Konflikt interesów}

Autorzy nie zgłaszają konfliktu interesów.

\section{Abstract}

Extracorporeal membrane oxygenation (ECMO) is used in cases of extreme respiratory and/or circulatory insufficiency, resistant to conventional treatment methods. As science moved on and experience was gained, ECMO began to be used also in the treatment of the most serious stages of hypothermia, as well as during the preparation for a planned heart and/or lung transplant. Due to restrictive guidelines and an invasive character of treatment, ECMO is undertaken relatively rarely. However, it often constitutes an element of therapy critical for patient's survival and further treatment possibilities.

Key words: ECMO, ECLS, extracorporeal circulation, extracorporeal membrane oxygenation

Folia Cardiologica 2017; 12, 1: 113-117 


\section{Piśmiennictwo}

1. Skalski JH, Religa Z. Kardiochirurgia dziecięca. „Śląsk” Wydawnictwo Naukowe, Katowice 2003.

2. Sangalli F, Patroniti N, Pesenti A, ECMO - extracorporeal life support in adults. Springer-Verlag, Italia 2014: 277.

3. Borowicz M, Urbańska E, Przybylski R, et al. ECMO jako metoda ratowania nie tylko noworodków, ale i dorosłych z niewydolnością krążenia i/lub oddychania, Kardiochir Torakochir Pol. 2008; 5(2): 183-186.

4. Darocha T, Kosiński S, Jarosz A, et al. Zasady postępowania w wychłodzeniu - małopolski program pozaustrojowego leczenia hipotermii. Kardiol. Pol. 2015; 73(9): 789-794, doi: 10.5603/kp.2015.0171.

5. ELSO adult respiratory failure supplement to the ELSO general guidelines version 1.3. December 2013.

6. Gundre P, Shah T, Kupfer Y, et al. Murray's acute lung injury score as a predictor of tracheostomy in critically ill patients. Chest. 2009; 136(4): 61S-i1-61S-i2, doi: 10.1378/chest.136.4_meetingabstracts.61s-i.

7. Stankiewicz A, Frank M, Dmitruk I, et al. Skuteczna terapia ostrej niewydolności oddechowej w przebiegu infekcji wirusem grypy A/H1N1 przy użyciu membranowego natleniania pozaustrojowego. Kardiochir. Torakochir. Pol. 2011; 4: 462-465.

8. Schmidt M, Pellegrino V, Combes A, et al. Mechanical ventilation during extracorporeal membrane oxygenation. Crit Care. 2014; 18(1): 203, doi: 10.1186/cc13702, indexed in Pubmed: 24447458.

9. Lango R, Szkulmowski Z, Maciejewski D, Kusza K. Protokół zastosowania pozaustrojowej oksygenacji krwi (ECMO) w leczeniu ostrej niewydolności oddechowej. Anest Intens Ter. 2009; XLI4: 253-258.
10. Szymanski FM, Filipiak KJ. Cardiogenic shock - diagnostic and therapeutic options in the light of new scientific data. Anaesthesiol Intensive Ther. 2014; 46(4): 301-306, doi: 10.5603/AlT.2014.0049, indexed in Pubmed: 25293483.

11. ELSO adult cardiac failure supplement to the ELSO general guidelines. December 2013.

12. Pozzi M, Banfi C, Grinberg D, et al. Veno-arterial extracorporeal membrane oxygenation for cardiogenic shock due to myocarditis in adult patients. J Thorac Dis. 2016; 8(7): E495-E502, doi: 10.21037/ /jtd.2016.06.26, indexed in Pubmed: 27499982.

13. Gulack BC, Hirji SA, Hartwig MG. Bridge to lung transplantation and rescue post-transplant: the expanding role of extracorporeal membrane oxygenation. J Thorac Dis. 2014; 6(8): 1070-1079, doi: 10.3978/j. issn.2072-1439.2014.06.04, indexed in Pubmed: 25132974.

14. Nolan J. European resuscitation council guidelines for resuscitation 2005. Resuscitation. 2005; 67: S3-S6, doi: 10.1016/j.resuscitation.2005.10.002.

15. Kosinski S, Górka A. Specyfika i czynniki ryzyka miejskiej postaci hipotermii. Anestezjologia i Ratownictwo. 2010; 4: 468-481.

16. Arrich J. European Resuscitation Council Hypothermia After Cardiac Arrest Registry Study Group. Clinical application of mild therapeutic hypothermia after cardiac arrest. Crit Care Med. 2007; 35(4): 1041-1047, doi: 10.1097/01.CCM.0000259383.48324.35, indexed in Pubmed: 17334257.

17. General guidelines for all ECLS cases, extracorporeal life support organization (ELSO). Version 1.3. December 2013. 